\title{
Educação bilíngue: uma breve discussão
}

Heloísa Augusta Brito de Mello (MELLO, Heloísa. A. B.)

Professora Doutora da Universidade Federal de Goiás - UFG

heloisabrito@brturbo.com.br

\section{Resumo}

Este trabalho tem como objetivo discutir a educação bilíngue em termos de conceituação, orientação e tipologias, tendo em vista o fato de que nem sempre se tem clareza sobre o que é e o que se espera de um programa de ensino bilíngue. Revisitando os estudos da área, esperamos reunir subsídios para discutir o que significa educar por meio de duas línguas uma população de alunos linguística e culturalmente diversa. Desse modo, problematizamos questões relativas a políticas linguísticas e educacionais e a orientações ideológicas subjacentes aos diversos modelos e tipos de programas bem como características contextuais e estruturais que definem um programa de ensino como bilíngue ou não.

Palavras-chave: educação bilíngue; ensino bilíngue; programas de imersão; programas de duas vias.

\begin{abstract}
Due to the fact that there is a lot of misunderstanding about what bilingual education is and what is expected from bilingual programs, this article aims at shedding some light on bilingual education issues such as concepts and definitions, typologies, language policies and ideological orientations underlying the different models and types of programs as well as their defining characteristics. Revisiting the studies in the area, we hope to bring up a discussion about what means to educate bilingually a cultural and linguistic diverse student population.
\end{abstract}

Keywords: bilingual education; bilingual programs, immersion programs; dual language programs.

\section{Introdução}

A educação bilíngue é um campo de ensino e pesquisa bastante controvertido, tanto no nível teórico quanto prático. Grosso modo, as questões que permeiam a educação bilíngue são complexas; os conceitos e pressupostos difusos e variados, muitos dos quais 
se sobrepõem ou não apresentam contornos claramente definidos. Na prática, nem sempre pais de alunos e corpo docente têm clareza sobre o que vem a ser educação bilíngue de fato, sobre seus objetivos e orientações, modelos e tipos de programas adequados às diferentes populações de alunos e, principalmente, sobre sua eficácia.

Como são muitas as variações de um contexto para outro, é importante ir além das discussões sobre o que significa educação bilíngue para investigar como e por que os programas bilíngues funcionam da maneira como são num determinado contexto sócio-

histórico. É sob esta perspectiva que discutimos inicialmente o conceito de educação bilíngue e de bilinguismo; em seguida apresentamos recortes da história da educação bilíngue nos cenários norte-americano, canadense e brasileiro com o intuito de mostrar que o ensino bilíngue é muito mais do que uma questão linguística; e por fim discutimos os principais modelos e tipos de programas descritos na literatura da área. Esperamos que essa discussão, mais do que elucidar as questões teóricas aqui abordadas, possa mostrar como funcionam alguns desses programas.

\section{O que se entende por educação bilíngüe?}

Dizer o que se entende por educação bilíngue nem sempre é uma tarefa fácil porque a sua caracterização extrapola os limites da escola e inclui outros agentes socializantes como a família, os amigos, a vizinhança, a sociedade maior, os meios de comunicação etc. (AKKARI, 1998). Além disso, envolve a compreensão de aspectos da história, da ideologia, da política e dos interesses individuais e coletivos da sociedade como as línguas são vistas e usadas na sociedade, o que significa educar uma população linguística e culturalmente diversa, o que se espera atingir e para quem são destinados os programas de ensino, entre outros.

Todavia, grande parte das definições de educação bilíngue é centrada na escola e nas inúmeras alternativas de ensino que têm sido utilizadas em diferentes contextos para diferentes populações de alunos. O resultado disso é que há uma miríade de termos e tipologias, muitas vezes coincidentes ou conflitantes, conforme aponta Hornberger (1991). Entre as discrepâncias mencionadas por essa autora estão, por exemplo, a inconsistência no uso de um mesmo termo ou expressão para referir-se a diferentes tipologias, como é o caso das inúmeras variações dos programas denominados de imersão, ou a proliferação de termos usados para uma mesma tipologia, como acontece 
com as expressões educação bilíngue transicional ou educação bilíngue de manutenção, que também são conhecidas por educação bilíngue compensatória (ou ainda assimilacionista, segregacionista, imersão estruturada, etc.) e educação bilíngue desenvolvimental (ou ainda educação de língua abrigada ${ }^{1}$ ou manutenção pluralística ou de grupo).

A própria expressão educação bilíngue tem sido usada de maneira abrangente para caracterizar diferentes formas de ensino nas quais os alunos recebem instrução (ou parte da instrução) numa língua diferente daquela que normalmente eles usam em casa. Vários são os modelos e tipos de educação bilíngue. Eles, porém, diferem quanto aos objetivos, às características dos alunos participantes, à distribuição do tempo de instrução nas línguas envolvidas, às abordagens e práticas pedagógicas, entre outros aspectos do uso das línguas e do contexto em que estão inseridos.

Apesar de a expressão educação bilíngue fazer referência a "duas línguas", muitos dos programas assim denominados proporcionam instrução acadêmica em apenas uma língua. De fato, esses programas são monolíngues, mas são popularmente considerados como bilíngues porque atendem a populações multiétnicas e seus alunos tornam-se bilíngues à medida que usam na escola uma língua diferente daquela que é falada regularmente em casa. Essa é a situação das crianças imigrantes que frequentam programas de ensino regular ${ }^{2}$ e recebem instrução na língua da sociedade em que vivem. Essa abordagem é conhecida como sink or swim $^{3}$ e o programa é denominado submersão ou imersão estruturada.

Uma variação desse tipo de programa é incorporar ao programa regular monolíngue algum tipo de suporte linguístico (por exemplo, aulas de $E_{S L}{ }^{4}$, no caso do inglês) ou acadêmico (por exemplo, uso de métodos e materiais especiais que auxiliam na instrução da L2) para as crianças que não falam a língua da escola, isto é, a L2. Em alguns casos, o uso da L1 na sala de aula é permitido, embora ela não seja oficialmente usada para fins instrucionais. Essa abordagem (ou programa) recebe, entre outras, as denominações segregacionista, segregação forçada, sheltered classes $^{5}$ ou pull-out

\footnotetext{
${ }^{1}$ Language shelter education. Para outras tipologias ver, por exemplo, o quadro-resumo de Hornberger (1991, p. 218-219) ou Genesee (1987).

2 Mainstream educational programs - programas de instrução monolíngue na língua majoritária para crianças do grupo majoritário.

${ }^{3}$ Ou nade ou afogue.

${ }^{4}$ English as a Second Language - Inglês como Segunda Língua.

${ }^{5}$ Aulas abrigadas. Nessas aulas, a professora geralmente usa uma forma simplificada da L2.
} 
classes ${ }^{6}$

Tecnicamente, a educação bilíngue corresponde àquela "em que duas línguas são usadas como meio de instrução" (HORNBERGER, 1991, p. 217) ou, nas palavras de Genesee (1987, p. 1), "educação bilíngue de verdade [grifo nosso] é a instrução que ocorre na escola em pelo menos duas línguas". Todavia, essas definições ainda são limitadas e imprecisas, pois em muitos casos a instrução por meio de duas línguas se limita à fase inicial da escolarização, como ocorre nos programas do tipo transicional. Nesses programas, a L1 das crianças, geralmente uma língua minorizada, é usada temporariamente até que a criança adquira as habilidades linguísticas e acadêmicas necessárias para acompanhar a instrução dos conteúdos na L2, isto é, na língua da sociedade receptora. O objetivo principal desse tipo de programa é promover a assimilação dos grupos minorizados à sociedade majoritária e, portanto, não visam ao bilinguismo, apesar de usarem ou permitirem o uso das duas línguas durante um determinado período.

Os programas de manutenção também fazem uso de duas línguas durante um período da escolarização, geralmente superior ao tempo que normalmente é destinado ao uso da L1 nos programas transicionais e diferem desses últimos porque têm objetivos pluralísticos e preservam a L1 dos alunos - alguns na modalidade oral, outros nas modalidades oral e escrita - enquanto eles desenvolvem a L2.

Outros programas têm objetivos pluralísticos de fato e fazem uso de duas línguas como meio de instrução ao longo de todo (ou quase todo) o processo de escolarização das crianças. Esses programas são implementados por meio da imersão total ou parcial na L2 durante uma fase inicial e, gradativamente, passam a distribuir o tempo de instrução entre as duas línguas ao longo dos anos numa proporção até de 50\% do tempo para cada língua. Nesses programas, destinados a alunos que integram os grupos minorizado e/ou majoritário, a L2 pode ser tanto uma língua majoritária quanto minorizada. Apesar de apresentarem uma grande variedade quanto às características estruturais e contextuais, esses programas denominados programas de imersão, de enriquecimento, de duas-línguas, de duas-vias têm como objetivo principal adicionar uma segunda ou terceira língua ao repertório linguístico das crianças.

Esse breve percurso pelas tipologias que se abrigam sob a expressão guardachuva educação bilíngue mostra que, apesar de haver certa inconsistência nas definições

\footnotetext{
${ }^{6}$ Aulas de acompanhamento linguístico.
} 
e discrepância entre as diversas tipologias registradas na literatura, há traços comuns entre elas. Essas similaridades permitem agrupar ou distinguir as tipologias quanto às características estruturais e contextuais, aos objetivos, às orientações subjacentes e às populações-alvo, entre outros aspectos.

Dessa forma, a expressão educação bilíngue tem sido frequentemente usada na sua acepção mais abrangente para incluir todas as situações em que duas ou mais línguas estão em contato, fazendo-se a distinção entre as suas diversas tipologias somente quando o contexto ou a situação requer um maior detalhamento técnico. De maneira semelhante, quando se usam as expressões escola bilíngue e/ou sala de aula bilíngue, faz-se referência à possibilidade de ocorrência de uso de mais de uma língua nesses contextos, mesmo quando se espera que uma única língua seja usada na maior parte das interações que ocorrem nesses contextos.

Nessa mesma perspectiva, o conceito de bilinguismo é também entendido de maneira abrangente como "a habilidade de uma pessoa de processar duas línguas" (WILLIAMS; SNIPPER, 1995, p. 33) quando ela interage com os seus pares no seu contexto social. Essa definição inclui não só as pessoas que fazem uso regular de duas ou mais línguas no seu cotidiano (GROSJEAN, 1982), mas também aquelas que estão em processo de desenvolvimento da competência bilíngue, como é o caso das crianças que são escolarizadas por meio de uma segunda língua. Portanto, o conceito de bilinguismo, nesse sentido, reflete tanto as características do indivíduo (graus variados de competência e diferentes modos de fala) quanto as características sociológicas do contexto (local, participantes, situação, tópico e a função da interação).

Como o contexto social é o principal fator que influencia os caminhos da educação bilíngue num determinado local, bem como a sua configuração, apresentamos nas seções seguintes um panorama histórico da educação bilíngue nos Estados Unidos, Canadá e Brasil. Os dois primeiros países são, talvez, os locais onde se concentra o maior número de pesquisas e experiências na área de educação bilíngue, o que, de certa forma, explica a profusão de termos e tipologias.

\section{Educação bilíngüe: recortes da história}

Os Estados Unidos são, talvez, um dos países que mais tem debatido a educação bilíngue nos últimos tempos, dada as particularidades de seu contexto sócio-histórico. 
Surgida na década de 60 como uma resposta política aos problemas educacionais das crianças que chegavam à escola falando uma língua diferente daquela que era usada como meio de instrução, a educação bilíngue assumiu, a princípio, características de ensino compensatório. Essas crianças tinham uma proficiência limitada no inglês e, quando comparadas com as crianças anglofalantes, apresentavam baixo rendimento e alto índice de abandono escolar.

Para sanar esses problemas, foram criados programas especiais cujo objetivo inicial era desenvolver a habilidade linguística dessas crianças no inglês, a fim de que rapidamente elas pudessem ser colocadas nos programas regulares de ensino. Portanto, no lugar de um ensino bilíngue surgiram programas de educação compensatória. Essa orientação, fundamentada, sobretudo, na ideologia do déficit cultural, serviu para que a educação bilíngue fosse associada ao fracasso acadêmico e aos grupos minorizados que vivem naquele país. Posteriormente, outros modelos e tipos de programas foram implementados - de manutenção, de enriquecimento, de duas-línguas, etc. -, mas a maioria deles continua sendo do tipo transicional porque seus objetivos não somente atendem à legislação americana no que diz respeito às políticas linguísticas e educacionais vigentes, mas também porque estão alinhados com os interesses políticos, ideológicos e econômicos das classes dominantes naquele país (GARCIA; BAKER, 1995; MORAES, 1996).

Hoje, após cinco décadas de pesquisas acerca dos modelos e da implementação dos diversos tipos de programas de educação bilíngue, há, ainda, muita polêmica em torno da questão. O panorama observado é o seguinte: o movimento English-Only, por exemplo, defende uma política monolinguística para o país e, consequentemente, integrativa para as minorias etnolinguísticas; a mídia faz críticas aos milhões de dólares que o governo destina à educação bilíngue, argumentando que os resultados são insatisfatórios porque as crianças não aprendem nem uma ou outra língua de fato; cidadãos comuns declaram-se cansados de pagar impostos para sustentar programas que não apresentam resultados positivos; até mesmo pais de alunos que representam os grupos minorizados posicionam-se contrários à educação bilíngue porque veem o ensinoaquisição do inglês como o único caminho para a ascensão social e econômica de seus filhos ${ }^{7}$. Em outras palavras, para esses pais, a educação bilíngue é um mal a ser evitado porque reforça o estigma da diferença, limitando, assim, as oportunidades futuras de

\footnotetext{
${ }^{7}$ Sobre avaliações e comentários recentes na mídia acerca da educação bilíngue nos Estados Unidos, ver, por exemplo, Matos (2001, p. 2E); Schlafly (1998); Chaves (2001, p. C2); Armas (2001, p. A8); López (1995).
} 
seus filhos naquele país.

Percebe-se, então, que as pesquisas sobre educação bilíngue avançam e apresentam resultados positivos, como se pode observar no estudo de Freeman (1998), mas forças contrárias, de alguma forma, os tornam invisíveis. Ao que tudo indica, essa orientação pró-inglês continua sendo refletida nas políticas linguísticas e nos planejamentos educacionais daquele país. Isso leva a supor que ainda hoje a diversidade linguística é vista naquele país como um problema, um empecilho para a americanização das crianças que falam uma L1 diferente do inglês.

$\mathrm{Na}$ verdade, essa orientação monolinguística pode ser explicada à luz da perspectiva política e econômica internacional. A posição de país dominante no cenário mundial tem sido traduzida em hegemonia linguística. Em todo o mundo, as pessoas acreditam que, para ser bem-sucedido econômica e socialmente, elas precisam saber inglês e isso, de certa forma, coloca todas as pessoas que falam essa língua numa posição confortável. Portanto, para muitos falantes nativos do inglês, não há por que se preocupar em aprender uma segunda língua.

No Canadá, a educação bilíngue também surgiu como uma resposta às demandas sociais das minorias linguísticas, porém seguiu percursos diferentes. Na verdade, ela é uma consequência dos movimentos de valorização da língua e da cultura francesa. Descontentes com a situação de inferioridade do francês na sociedade, particularmente na região de Quebec, a comunidade francofônica começou a expressar publicamente sua insatisfação diante das desigualdades linguísticas e culturais existentes. Esses movimentos despertaram a atenção da comunidade anglofalante que passou a conscientizar-se da crescente importância do francês para a comunicação em todas as esferas sociais da província, principalmente no mercado de trabalho. Um grupo de pais anglofalantes, preocupados com as barreiras linguísticas e culturais que separavam as duas comunidades, passou a reunir-se informalmente para discutir a situação e acabaram apresentando uma proposta de adição de uma segunda língua, o francês, ao repertório linguístico das crianças anglofalantes. Esperava-se, dessa forma, possibilitar uma melhor interação entre anglo e francofalantes, sem, no entanto, esperar que as crianças que frequentavam esses programas se tornassem francesas. Essa proposta foi implementada em 1965, a título experimental, numa escola da comunidade de St. Lambert, periferia de Montreal (GENESEE, 1987).

Resumidamente, o programa de ensino proposto caracterizava-se, sobretudo, pela sua orientação aditiva de línguas e pelo uso da segunda língua, desde os anos iniciais, para ensinar disciplinas regulares do currículo, tais como matemática e ciências, 
além da própria língua. Pretendia-se, assim, proporcionar condições para uma aprendizagem acidental da L2 à medida que as crianças progrediam linguística e academicamente nos anos subsequentes. Inicialmente, o francês era usado como único meio de instrução; posteriormente, ao final do segundo ou terceiro ano, a instrução do e no inglês era gradativamente introduzida até atingir uma proporção de aproximadamente $60 \%$ do tempo de instrução para o inglês e $40 \%$ para o francês. Esperava-se com essa estrutura que as crianças desenvolvessem as duas línguas em níveis - linguísticos e acadêmicos - satisfatórios para que pudessem agir como indivíduos funcionalmente bilíngues.

A partir daí, os programas de imersão evoluíram e assumiram as diferentes formas que podem ser encontradas em todas as províncias do Canadá e em diversas regiões dos Estados Unidos. Embora em ambos os países a educação bilíngue tenha surgido como uma resposta a um problema político-sociolinguístico, no Canadá a busca dessa resposta tinha como premissas básicas tanto o estabelecimento de um bilinguismo do tipo aditivo quanto a integração social de comunidades linguística e culturalmente distintas, ao passo que nos Estados Unidos a solução para o problema fundamentava-se na perspectiva de um bilinguismo do tipo subtrativo e na assimilação de uma cultura pela outra.

Essa diferença de perspectivas leva, muitas vezes, a diferentes interpretações sobre o significado da educação bilíngue nesses dois contextos: um associa a educação bilíngue ao fracasso e, por isso, a vê como um problema que deve ser remediado; o outro vislumbra o sucesso na educação bilíngue e a concebe como um bem cultural que deve ser preservado.

No Brasil, a educação bilíngue está estereotipicamente associada à educação para os povos indígenas ou às línguas de prestígio internacional (inglês, francês, espanhol, etc.), convencionalmente denominada educação bilíngue de elite. Segundo Cavalcanti (1999), falar em educação bilíngue em nosso contexto causa, até mesmo, certa estranheza, para a qual essa autora aponta três razões. Primeiro, assim como em outros países, há no Brasil o mito do monolinguismo, herança deixada pelos colonizadores portugueses. Esse mito tem sido capaz de apagar as minorias linguísticas e dialetais existentes no país, isto é, as nações indígenas, as comunidades de imigrantes e as comunidades que falam variedades sem prestígio do português (BORTONIRICARDO, 1984; BAGNO, 1999). Segundo, porque o acesso ao ensino das línguas de prestígio internacional é um privilégio de poucos. Apenas uma parcela muito pequena 
da sociedade brasileira pode arcar com os custos de uma educação bilíngue para seus filhos em escolas americanas ou francesas, que adotam como meio de instrução suas respectivas línguas nacionais, ou em centros especializados de línguas estrangeiras. Em terceiro lugar, esses contextos "são (tornados) invisíveis, portanto naturalizados" (CAVALCANTI, 1999, p. 387) aos olhos da sociedade, ou porque predomina a imagem de país monolíngue, ou porque as línguas faladas pelas comunidades indígenas são estigmatizadas, ou porque as variedades do português faladas nos contextos bidialetais/rurbanos (BORTONI-RICARDO, 1984) são também desprezadas, ou porque as línguas faladas nas comunidades de imigrantes têm sido tradicionalmente silenciadas, ou ainda porque são excludentes. Portanto, “depreende-se que o Brasil não reconhece e não encoraja o ensino bilíngue [...] a exceção fica com as comunidades indígenas, que têm na Constituição de 88 o direito assegurado para a educação bilíngue" (CAVALCANTI, 1999, p. 395).

A educação bilíngue para os povos indígenas, segundo Braggio (2001, manuscrito), tem início oficialmente em 1972, quando se prevê que a educação dos grupos indígenas com "problemas linguísticos” será sempre bilíngue. Pela própria formulação da lei, comenta a autora, pode-se depreender que os programas de ensino dessa época estavam pautados numa orientação que vê a língua como um problema. Dada a situação sociolinguística na qual a língua indígena é a primeira língua adquirida pela criança, a educação bilíngue é entendida, nessa perspectiva, como uma ponte de transição para a aquisição da língua e da cultura dominante. Nesse modelo, a língua indígena passa a ser usada na escola apenas com a função de traduzir e facilitar a aquisição do português e dos conhecimentos necessários à integração do indígena na sociedade brasileira.

Só posteriormente, com a promulgação da Constituição Brasileira de 1988, há uma mudança nesse contexto e o "Estado reconhece o direito à alteridade e ao pluralismo cultural e linguístico [dos povos indígenas] e não mais insiste na posição de integração/assimilação" (BRAGGIO, 2001, manuscrito). ${ }^{8}$ Segundo essa mesma autora, a partir daí, foi possível estruturar o modelo atual de educação escolar para os indígenas: "diferenciado, específico, bilíngue e intercultural", deixando de ter, portanto, o caráter transicional presente no modelo anterior. Hoje, apesar do avanço do modelo de ensino atual, "muito há ainda por se fazer para que as escolas indígenas conquistem a

\footnotetext{
${ }^{8}$ Esses direitos estão registrados no Capítulo VIII, artigos 210, 215 e 231 da Constituição Brasileira de 1988.
} 
autonomia curricular e administrativa reivindicada" (RCNEI, 1998, p. 39).

No que se refere a outras comunidades de fala, pode-se afirmar que não há uma política linguística e educacional multilíngue no país. Apesar de o contingente imigratório europeu integrado à população brasileira ser avaliado entre 5 e 7 milhões de pessoas (RIBEIRO, 2006[1992]), além dos negros trazidos da África, o Brasil tem conseguido abafar todas essas vozes e manter a sua imagem de país monolíngue. Incluem-se aqui as comunidades alemãs, italianas, asiáticas, libanesas, polonesas, ucranianas, holandesas, austríacas, para nomear algumas, que mantêm ou não sua língua de origem, além dos contextos de fronteira com os países hispanofalantes.

Assim, no caminho para a homogeneidade cultural básica, a sociedade e a escola brasileiras, desde os seus primórdios, têm contribuído para o silenciamento dos povos que falam uma língua diferente daquela tomada como a língua nacional, isto é, o português. Primeiro, os colonizadores instituíram as escolas religiosas cujo objetivo era ensinar o português aos nativos para que mais facilmente pudessem catequizá-los; posteriormente, quando vieram os escravos da África, suas línguas e dialetos foram rapidamente apagados em razão da necessidade de adaptarem-se ao novo universo cultural e social; em seguida, quando os escravos foram substituídos pelos imigrantes europeus, em pouco tempo, o país cerceou-lhes o direito de aprender suas línguas de origem na escola; e, ainda hoje, a escola brasileira não reconhece o direito das crianças brasileiras ou não - que vivem nos contextos de fronteira - de aprender na escola as línguas com as quais interagem regularmente no seu cotidiano.

De fato, esses grupos sempre foram negligenciados no currículo escolar, especialmente durante os anos do governo Getúlio Vargas (1937-1945) e, posteriormente, no período da ditadura militar (MORAES, 1996). Imbuídos de sentimentos de nacionalismo, esses governos se propuseram a unificar a língua e a cultura brasileira para que se pudesse, então, imprimir uma única identidade nacional. Para tal, várias medidas governamentais foram implementadas para restringir a atividade social e política dos estrangeiros nessa época.

Os imigrantes não mais poderiam viver separadamente em suas próprias colônias culturais. Os jornais escritos em língua estrangeira foram proibidos e os logradouros ou estabelecimentos comerciais que tinham nomes estrangeiros foram mudados para o português. Exigiuse que todas as escolas tivessem diretores brasileiros e que toda a instrução fosse dada em Português e os pais não mais poderiam mandar seus filhos para estudarem em escolas do exterior. (NAVA, 1993, p. 11, apud MORAES, 1996, p. 2-3) 
Hoje, apesar da mudança de cenário em termos sociopolíticos, a orientação monolinguística ainda predomina em nosso país. As escolas públicas seguem um currículo nacional que requer o ensino de uma língua estrangeira para os alunos do ensino fundamental $\left(6^{\circ}\right.$ ao $9^{\circ}$ ano) e médio, porém o ensino dessa língua estrangeira tem sido, em geral, negligenciado, sem visar a um bilinguismo de fato. ${ }^{9}$ Essa língua estrangeira tem sido tradicionalmente o inglês, desde a reforma educacional (Lei de Diretrizes e Bases) de 1971, promovida pelo governo da ditadura militar e com o suporte do governo dos Estados Unidos (MORAES, 1996). No passado, o francês também teve seus momentos áureos no nosso ensino de línguas estrangeiras, mas foi pouco a pouco substituído pelo inglês; o futuro aponta para a ascensão do espanhol, em decorrência dos acordos de cooperação entre os países do Cone Sul, mas a implementação dessa língua nas escolas públicas ainda é incipiente.

As escolas internacionais que proporcionam instrução em duas línguas e os centros binacionais ou institutos de idiomas (Centro Cultural Brasil-Estados Unidos, Cultura Inglesa, Aliança Francesa, Instituto Ibero-Americano, Instituto Goethe, etc.) que ensinam a língua e a cultura de seus respectivos países representam pequenas ilhas na imensidão do nosso território, apesar de estarem eclodindo em várias capitais do país escolas que se autodenominam bilíngues. Entre essas, apenas as primeiras proporcionam educação básica em duas línguas e têm seus currículos reconhecidos pelo Ministério da Educação Cultura e Desportos. As segundas oferecem apenas instrução complementar em uma língua estrangeira e não são nem mesmo consideradas como escolas; são entidades prestadoras de serviço e como tais não estão sujeitas às exigências educacionais previstas no sistema nacional de ensino. Conforme já mencionado, apenas uma parcela muito pequena da sociedade brasileira tem acesso a esse tipo de ensino, sendo, portanto, despido de qualquer representatividade em termos da população nacional e do sistema educacional brasileiro.

Diante desses cenários parece claro que a educação bilíngue está diretamente relacionada à história, à ideologia e à organização sociopolítica de um povo e, por isso, segue caminhos diferentes. São esses diversos caminhos que deram origem aos diferentes modelos e tipos de programas de ensino bilíngue que focalizamos a seguir.

\footnotetext{
${ }^{9}$ Por bilinguismo de fato entendemos a capacidade de um indivíduo de usar a língua estrangeira nas suas diversas modalidades (fala, escrita, leitura e compreensão).
} 


\section{Modelos e tipos de programas de educação bilíngue}

Iniciamos esta revisão com a tipologia proposta por Hornberger (1991) por considerá-la mais esclarecedora e por acomodar as diversas variações de ensino bilíngue. Primeiramente, ela faz a distinção entre modelos e tipos de programas de educação bilíngue, incluindo os primeiros numa categoria mais ampla e num nível de abstração maior do que os segundos. Os modelos são definidos em termos dos objetivos dos planejamentos linguísticos e educacionais e das orientações ideológicas em relação à diversidade linguística e cultural na sociedade; já os tipos de programas são norteados pelas características contextuais e estruturais específicas.

Por orientações, Hornberger (1991) entende a maneira como as línguas são vistas na sociedade, isto é, o valor, o status e as funções que elas têm na sociedade e as atitudes das pessoas em relação às línguas e aos seus falantes. Por características contextuais, ela quer dizer a natureza da população de alunos (nativos, imigrantes ou nativos em situação minoritária, número, status socioeconômico, L1, etc.). Por características estruturais, ela designa a situação do programa na escola (se atinge toda a população de alunos ou se é destinado apenas a uma parcela), a distribuição das línguas no currículo (pela proporção do tempo de instrução, por períodos, por disciplinas) e os padrões de uso das línguas na escola (quais línguas são usadas para quais finalidades na sala de aula ou na escola como um todo). Essa distinção é importante porque permite compreender as diferenças entre os vários programas de ensino bilíngue - como e por que variam, suas orientações, suas características contextuais e estruturais específicas.

Hornberger (1991) identifica três modelos de educação bilíngue: transicional, de manutenção e de enriquecimento. O modelo transicional caracteriza-se pelos seus objetivos assimilacionistas, por encorajarem os alunos das minorias linguísticas a assimilar a língua e as normas culturais da sociedade majoritária em detrimento das línguas étnicas ${ }^{10}$. Os programas educacionais que adotam esse modelo valorizam a proficiência das crianças na língua dominante da escola (L2 para as minorias linguísticas) para que elas possam funcionar linguística e academicamente nas salas de ensino regular. A L1 é usada como meio de instrução durante uma fase temporária da

\footnotetext{
${ }^{10}$ Por língua majoritária entende-se a língua que tem maior valor na sociedade, geralmente a língua oficial e/ou nacional; por línguas étnicas e/ou minorizadas entendem-se as línguas que têm menor prestígio nessa mesma sociedade.
} 
escolarização, até que as crianças possam fazer a transição para a L2. Em muitos casos a assimilação (por exemplo, nos contextos em que as línguas concorrem de maneira bastante assimétrica, nos casos em que o uso da língua está decrescendo ou quando há um enfraquecimento da identidade cultural) pode significar a perda da língua e da cultura minoritária porque as crianças deixam de usar a L1 à medida que são pressionadas a usar a língua majoritária. Em síntese: o objetivo principal desses programas não é o bilinguismo, mas o monolinguismo na língua majoritária. De acordo com Ruiz (1991) os modelos transicionais concebem a língua como um problema e, por isso, a L1 só é usada até que a criança supere esse problema, isto é, a "deficiência" na língua majoritária. Na perspectiva de Lambert (1987), essa é uma orientação subtrativa de línguas.

O modelo de manutenção, também denominado desenvolvimental, é caracterizado pelos seus objetivos pluralísticos, pelo encorajamento da manutenção da língua minoritária e pela reafirmação da identidade cultural e dos direitos civis dos grupos minoritários na sociedade nacional. Os programas que seguem essa orientação têm dois objetivos quanto ao planejamento linguístico: desenvolver a L1 e proporcionar a aquisição da L2. Assim como nos programas transicionais, nos de manutenção os alunos também são segregados em salas especiais (pull-out classe) para que recebam instrução por meio da L1, porém por um período maior do que os primeiros, para que eles tenham a oportunidade de desenvolver linguística e academicamente a língua minoritária enquanto adquirem a majoritária. Os programas que seguem esse modelo vêem a língua como um direito, incentivam a manutenção da língua minoritária (RUIZ, 1991) e têm, portanto, uma orientação aditiva de línguas (LAMBERT, 1987) porque não pressionam os alunos a usar apenas a língua majoritária, mas, ao contrário, esperam que eles sejam proficientes na L1 e L2.

O modelo de enriquecimento é também caracterizado pelos seus objetivos pluralísticos e pela sua orientação aditiva de línguas, porém com a diferença de que, em termos de planejamento linguístico, os programas que seguem essa orientação são destinados tanto à população minoritária quanto à majoritária. A língua nesses programas é vista como um recurso tanto para os alunos das minorias linguísticas como para os do grupo majoritário (RUIZ, 1991). Espera-se que a língua minoritária não seja apenas preservada, mas, sobretudo, desenvolvida e usada como um recurso tanto para o indivíduo quanto para a sociedade nacional. Ela é mais do que um direito para os seus falantes, ela é um recurso potencial para os falantes da língua majoritária (HORNBERGER, 1991). A 
estratégia usada nesses programas é a da não-segregação dos alunos em salas especiais, diferentemente do que ocorre em relação aos programas anteriores. Acredita-se que os alunos auxiliam-se mutuamente e juntos constroem o conhecimento linguístico (nas duas línguas) ou conteudístico (nas diversas disciplinas). Ao invés da separação dos alunos segundo as diferentes línguas, os programas que seguem o modelo de enriquecimento usam as duas línguas como meio de instrução e as distribuem no currículo de forma variada - por áreas do conhecimento, por períodos diários ou dias da semana, pela proporção do tempo alocado para cada língua ou por uma combinação desses critérios.

Apesar de os programas de transição e manutenção também utilizarem a língua minoritária como meio de instrução para as crianças dos grupos minoritários, Freeman (1998) salienta que a diferença fundamental está no valor que é dado à língua minoritária. Nos programas que seguem o modelo de enriquecimento, a língua minoritária é oficialmente um meio legítimo de instrução não só para esses grupos, mas também para os alunos que falam a língua majoritária. Isso serve, segundo essa autora, para elevar o status da língua minoritária no contexto da escola e da comunidade nacional, ao mesmo tempo em que estabelece uma política linguística multilíngue de fato.

O Quadro 1 mostra um resumo dos modelos de educação bilíngue propostos por Hornberger (1991).

Quadro 1. Modelos de educação bilíngue (adaptado de Hornberger (1991, p. 223))

\begin{tabular}{|c|c|c|}
\hline Transicional & De Manutenção & De Enriquecimento \\
\hline Perda da língua & Manutenção da língua & Desenvolvimento da língua \\
\hline Assimilação cultural & Reforço da identidade cultural & Pluralismo cultural \\
\hline Incorporação social & Afirmação dos direitos civis & Autonomia social \\
\hline
\end{tabular}

Essa classificação sugere que esses modelos podem dar origem a diferentes tipos de programas de ensino bilíngue, assim como qualquer tipo de programa pode ter orientações do tipo transicional, de manutenção ou de enriquecimento. Isso significa que um programa do tipo de imersão pode ser incluído em qualquer um desses modelos, dependendo de suas orientações, objetivos e características. Hornberger (1991) espera com essa tipologia oferecer critérios paralelos entre os programas no que concerne às suas características estruturais, contextuais e às orientações que fundamentam o planejamento linguístico da escola.

Os programas que se enquadram na categoria transicional são aqueles que têm 
recebido o maior número de críticas na literatura da área porque têm uma orientação subtrativa de línguas e, principalmente, porque classificam os alunos que falam a língua minoritária em termos de suas "deficiências", estigmatizando-os aos olhos dos demais (BAKER, 1993; BAKER, 1995; CUMMINS, 1996; GARCIA; RUIZ, 1991).

Os modelos de manutenção e de enriquecimento também têm seus opositores, que alegam que nos contextos multilíngues nem sempre se pode proporcionar instrução em todas as línguas faladas como L1 pela população de alunos, em virtude da falta de professores qualificados na língua minoritária, da falta de material didático adequado, da grande diversidade étnica numa mesma sala de aula, etc. Por essas razões, a escola acaba escolhendo uma ou duas entre várias línguas minoritárias. Outra alegação é a de que a instrução na L1 reduz o tempo de exposição dos alunos à L2 (princípio da exposição máxima), prejudicando, assim, o desenvolvimento da proficiência na L2.

Cummins (1996) apresenta uma discussão bastante esclarecedora acerca dos argumentos favoráveis e contrários aos modelos transicionais e de enriquecimento. Grosso modo, esse autor sugere que há aqueles que acreditam que as crianças não podem aprender numa língua que não compreendem. Para elas, a instrução na L1 é necessária para minimizar os efeitos negativos do descompasso entre a língua da escola e a língua da casa. Em oposição a essa abordagem, há aqueles que consideram ilógico pensar que uma menor exposição à L2 leva a um maior desenvolvimento nessa língua. Para eles parece fazer mais sentido proporcionar aos aprendizes exposição máxima à L2. Apesar da aparente plausibilidade de cada uma dessas posições, Cummins (1996) argumenta que essas duas hipóteses são inadequadas, pois a resposta para essas duas suposições estaria no princípio da interdependência linguística, isto é, a proficiência na L1 e a na L2 seriam interdependentes. Por essa razão, esse autor acredita que os modelos de enriquecimento são mais adequados quando o objetivo é o desenvolvimento de uma proficiência bilíngue de fato.

Tomando como parâmetro a população-alvo, esse autor (1996) relaciona quatro tipos de programas de educação bilíngue. Os programas do Tipo I são aqueles destinados às populações indígenas - que foram conquistadas ou colonizadas em algum momento no passado - para reavivar ou resgatar o prestígio das línguas indígenas, a maioria delas sob ameaça de extinção. A exemplo do que ocorreu no Brasil e em muitos outros países, a maioria desses programas, no passado, tinha por objetivo ensinar a língua do colonizador e, dessa forma, promover a assimilação dos indígenas à sociedade dominante. 
Os programas do Tipo II visam à manutenção e revitalização de uma língua minoritária nacional, a exemplo do que ocorre no Canadá. A língua minoritária, nesse caso, tem - ou já teve - algum prestígio social ou é oficialmente reconhecida. A maioria desses programas é do tipo de imersão na língua-alvo ou de duas línguas.

Os programas do Tipo III envolvem as línguas minoritárias internacionais, geralmente aquelas usadas por imigrantes no país que os recebeu. A maioria dos programas bilíngues dos Estados Unidos se enquadra nessa categoria e tem como população-alvo as crianças que falam em casa uma língua diferente da língua da escola. Muitos são do tipo transicional e se propõem a facilitar a aquisição de conhecimentos e o desenvolvimento acadêmico dos alunos.

Os programas do Tipo IV, destinados ao grupo linguístico majoritário, têm por objetivo adicionar uma segunda língua ao repertório linguístico dos alunos. É o caso, por exemplo, tanto dos programas de duas línguas no Canadá quanto dos de imersão na língua-alvo oferecidos pelas escolas internacionais no Brasil, estes últimos referidos como programas bilíngues de elite ou bilinguismo de escolha (CAVALCANTI, 1999).

Cummins (1996) salienta que essa classificação não é estática. Em algumas situações, alguns programas podem ser classificados tanto como Tipo I ou II, a exemplo da comunidade Quéchua no Peru, que é vista como população indígena. Em outras situações, os programas do Tipo II e III são convergentes, ou melhor, sobrepõem-se como no caso dos programas bilíngues americanos (inglês-espanhol) que atendem às comunidades hispânicas nativas e aos grupos de imigrantes hispânicos recentes. Os programas de duas línguas (Tipo IV) também podem ser considerados como Tipo II e III porque também servem às minorias linguísticas em alguns contextos (Quadro 2).

Quadro 2. Tipos de programas bilíngues (elaborado com base em Cummins (1996))

\begin{tabular}{|c|c|c|c|}
\hline Tipo I & Tipo II & Tipo III & Tipo IV \\
\hline $\begin{array}{c}\text { Populações } \\
\text { indígenas }\end{array}$ & $\begin{array}{c}\text { Populações que falam } \\
\text { uma língua minoritária } \\
\text { nacional }\end{array}$ & $\begin{array}{c}\text { Populações que falam } \\
\text { uma língua } \\
\text { minoritária } \\
\text { internacional }\end{array}$ & $\begin{array}{c}\text { Populações que } \\
\text { falam a língua } \\
\text { majoritária }\end{array}$ \\
\hline $\begin{array}{c}\text { Modelos } \\
\text { transicionais e/ou } \\
\text { de manutenção }\end{array}$ & $\begin{array}{c}\text { Modelos de } \\
\text { manutenção ou de } \\
\text { enriquecimento }\end{array}$ & $\begin{array}{c}\text { Modelos } \\
\text { transicionais, de } \\
\text { manutenção ou de } \\
\text { enriquecimento }\end{array}$ & $\begin{array}{c}\text { Modelos de } \\
\text { enriquecimento }\end{array}$ \\
\hline $\begin{array}{c}\text { Língua indígena e } \\
\text { língua majoritária }\end{array}$ & $\begin{array}{c}\text { Língua minoritária } \\
\text { nacional e língua } \\
\text { majoritária }\end{array}$ & $\begin{array}{c}\text { Língua minoritária } \\
\text { internacional e língua } \\
\text { majoritária }\end{array}$ & $\begin{array}{c}\text { Geralmente uma } \\
\text { língua de prestígio } \\
\text { internacional ou } \\
\text { uma língua nacional }\end{array}$ \\
\hline
\end{tabular}


Como a literatura registra uma terminologia bastante variada e, às vezes, confusa para classificar os tipos de programas de educação bilíngue, focalizamos, a seguir, os programas de imersão e as suas diversas variações. Apesar de algumas tipologias dos programas de imersão já terem sido mencionadas anteriormente e, de certa forma, discutidas, optamos por caracterizá-las mais detalhadamente em razão não só de suas inúmeras variações, mas também porque o que se aplica a um contexto nem sempre é verdadeiro para outro, como é o caso dos programas denominados imersão nos contextos dos Estados Unidos e do Canadá. Ainda que muitos programas americanos de imersão tenham sido inspirados no modelo canadense, eles guardam entre si diferenças fundamentais quanto às características, orientação e política de uso das línguas.

\section{Programas de imersão}

Os programas de imersão do tipo canadense são, segundo Genesee (1987, p. 1), "uma forma de educação bilíngue na qual os alunos que falam a língua da maioria da população recebem uma parte de sua instrução por meio de uma segunda língua e outra parte por meio de sua primeira língua" (Tipo IV na classificação de Cummins). A distribuição das línguas no programa é feita, geralmente, com base no número de horas de instrução e nas disciplinas do currículo ou nos períodos de instrução (diários ou semanais). Por exemplo, L1 e L2 são usadas numa proporção de $10-90 \%$ ou $40-60 \%$, respectivamente, do tempo total de instrução; ou a L1 é usada para ministrar matemática e ciências, enquanto a L2 é usada para geografia e história, além da instrução das línguas propriamente ditas (francês-inglês, por exemplo); ou a L1 é usada no período da manhã e a L2 no período da tarde; ou ainda de acordo com os dias da semana (segunda, quarta e sexta-feira: francês; terça e quinta-feira: inglês).

O tipo mais comum é o de imersão total. Geralmente, nesse tipo de programa, a L2 é a única língua de instrução durante os primeiros anos escolares da criança (jardimde-infância até o $2^{\circ}$ ano do ensino fundamental); posteriormente, a L1 vai sendo introduzida no currículo numa proporção que pode variar de $10 \%$ a $50 \%$ do total das horas de instrução. Como o objetivo desses programas é a proficiência nas duas línguas, uma de suas características marcantes é o uso da L2 para a instrução de conteúdos variados em classes mistas, isto é, que reúnem alunos dos grupos minorizados e majoritário. Espera-se, assim, que a aprendizagem da L2 seja acidental e ocorra 
naturalmente no convívio com falantes nativos das duas línguas, ao invés de formal e puramente centradas no ensino das estruturas da língua (KRASHEN, 1981, 1985; SCHMIDT, 1990).

Os programas americanos de imersão têm, geralmente, orientações e objetivos diferentes. Alguns são também conhecidos como programas de submersão (sink or swim), que, de acordo com McKay (1991), são aqueles nos quais as crianças dos grupos minorizados são colocadas nas classes regulares ministradas apenas em inglês, sem que a escola ofereça qualquer tipo de apoio formal para que os alunos adquiram a línguaalvo. Cabe à professora daquele ano, que em geral não é proficiente na L1 das crianças, lidar com os problemas que elas possam ter. Para os adeptos desses programas as crianças adquirem rápida e facilmente a língua estrangeira quando interagem naturalmente com falantes nativos. Por isso, acreditam que quanto mais cedo elas se integram na sociedade receptora, maiores são as chances de sucesso acadêmico. $\mathrm{Na}$ verdade, os programas de submersão não são bilíngues, a não ser pelo fato de que atendem uma população que fala uma língua diferente da língua da escola.

Os programas americanos de imersão mais comuns (Tipo III na classificação de Cummins), por sua vez, incluem a instrução na L1 das crianças durante os primeiros anos de escolarização, até que elas possam participar linguística e academicamente das classes regulares. Em geral, essa instrução ocorre em salas especiais ou de ESL. As aulas de ESL têm por objetivo acelerar o desenvolvimento da competência em inglês e são, geralmente, centradas na instrução da língua. Esses programas pressupõem que a instrução formal na L2 é benéfica para o desenvolvimento da proficiência linguística dos alunos e, por isso, segregam os alunos em salas especiais. Uma das críticas a esses programas é que, por terem uma orientação transicional, a diversidade linguística é vista como um problema a ser superado pelas crianças que falam uma língua diferente da língua da escola e, dessa forma, elas corre o risco de serem consideradas linguística e academicamente deficientes.

Outras variações dos programas de imersão são aqueles denominados imersão em duas-línguas, ou imersão de duas-vias, imersão bilíngue, programas de enriquecimento, entre outras. ${ }^{11}$ Esses programas são cada vez mais comuns no Canadá e Estados Unidos (FREEMAN, 1998; C.A.L., 2001) e diferem dos anteriores,

${ }^{11}$ Dual-language programs, two-way programs, bilingual immersion programs, enrichment programs. 
principalmente, quanto à orientação, objetivos e estrutura. ${ }^{12}$ São mais conhecidos como programas de enriquecimento porque têm uma orientação aditiva de línguas, isto é, as línguas minoritária e majoritária são vistas como um recurso para toda a população de alunos. Na prática, isso significa que os alunos dos grupos minorizados aprendem a língua majoritária, enquanto os alunos do grupo majoritário aprendem a língua minorizada. Dessa forma, espera-se que ambas as línguas tenham prestígio dentro da escola e que os alunos desenvolvam atitudes positivas em relação às línguas e aos seus falantes, independentemente de pertencerem aos grupos minorizado ou majoritário (GENESEE, 1987).

As variações para os programas de imersão não se esgotam por aí, pois estão condicionadas às variáveis contextuais e estruturais, conforme já foi mencionado. A partir das tipologias sugeridas por Hornberger (1991), Cummins (1996) e Genesee (1987) pode-se perceber que várias são as combinações possíveis em relação aos tipos de educação bilíngue. O Quadro 3 resume algumas dessas características.

Quadro 3. Variações dos programas de imersão (elaborado com base em Hornberger (1991), Cummins (1996) e Genesee (1987))

\begin{tabular}{|c|c|c|c|c|}
\hline $\begin{array}{l}\text { Tipos de } \\
\text { programas }\end{array}$ & Instrução & $\begin{array}{c}\text { Tempo de } \\
\text { instrução L1/L2 }\end{array}$ & População-alvo & $\begin{array}{l}\text { Orientaçãa/ } \\
\text { Modelo }\end{array}$ \\
\hline $\begin{array}{l}\text { Submersão } \\
\text { (Americano) }\end{array}$ & L2 & $100 \%$ L2 & $\begin{array}{c}\text { Minorias } \\
\text { linguísticas }\end{array}$ & Subtrativa \\
\hline $\begin{array}{c}\text { Imersão } \\
\text { (Americano) }\end{array}$ & $\begin{array}{c}\text { L2/ESL } \\
\text { L1 usada p/ } \\
\text { facilitar aquisição } \\
\text { de conhecimentos }\end{array}$ & $\begin{array}{l}\text { L2 usada na maior } \\
\text { parte do tempo }\end{array}$ & $\begin{array}{l}\text { Minorias } \\
\text { linguísticas }\end{array}$ & $\begin{array}{l}\text { Subtrativa } \\
\text { Transicional }\end{array}$ \\
\hline $\begin{array}{c}\text { Imersão Total } \\
\text { Imersão } \\
\text { Parcial } \\
\text { Imersão } \\
\text { Tardia } \\
\text { (Canadenses) } \\
\end{array}$ & $\begin{array}{c}\text { L1/L2 } \\
\text { Língua e } \\
\text { Conteúdos }\end{array}$ & $\begin{array}{l}\text { Variável L2:100\% } \\
\left(\mathrm{Jd}-2^{\circ} \text { ano }\right) \\
\text { L1: a partir do } 3^{\circ} \\
\text { ou } 5^{\circ} \text { ano }\end{array}$ & $\begin{array}{l}\text { Grupo majoritário } \\
\text { (podendo incluir o } \\
\text { grupo minoritário) }\end{array}$ & $\begin{array}{c}\text { Aditiva } \\
\text { De } \\
\text { enriquecimento }\end{array}$ \\
\hline $\begin{array}{c}\text { Imersão por } \\
\text { Herança } \\
\text { Linguística } \\
\text { (Canadense) }\end{array}$ & $\begin{array}{l}\text { L1/L2 } \\
\text { Língua e } \\
\text { Conteúdos }\end{array}$ & $\begin{array}{l}\text { Variável ao longo } \\
\text { dos anos }\end{array}$ & Minorias étnicas & $\begin{array}{c}\text { Aditiva } \\
\text { De manutenção }\end{array}$ \\
\hline
\end{tabular}

${ }^{12}$ De acordo com os dados estatísticos do C.A.L. (Center for Applied Linguistics), o número de programas do tipo imersão em duas línguas (modelo de enriquecimento) tem crescido significativamente nos Estados Unidos: em pouco mais de dez anos eles passaram de 38 para 260. 


\begin{tabular}{|c|c|c|c|c|}
\hline $\begin{array}{l}\text { Tipos de } \\
\text { programas }\end{array}$ & Instrução & $\begin{array}{c}\text { Tempo de } \\
\text { instrução } \mathrm{L} 1 / \mathrm{L} 2\end{array}$ & População-alvo & $\begin{array}{l}\text { Orientação/ } \\
\text { Modelo }\end{array}$ \\
\hline $\begin{array}{c}\text { Imersão } \\
\text { Dupla } \\
\text { (Canadense) }\end{array}$ & $\begin{array}{l}\text { L1/L2/L3 } \\
\text { Língua e } \\
\text { Conteúdos }\end{array}$ & $\begin{array}{c}\text { Variável ao longo } \\
\text { dos anos }\end{array}$ & $\begin{array}{c}\text { Grupos } \\
\text { minoritários } \\
\text { (podendo incluir o } \\
\text { grupo majoritário) }\end{array}$ & $\begin{array}{c}\text { Aditiva } \\
\text { De manutenção } \\
\text { De } \\
\text { enriquecimento }\end{array}$ \\
\hline $\begin{array}{c}\text { Imersão de } \\
\text { Duas-línguas } \\
\text { (Americano e } \\
\text { Canadense) }\end{array}$ & $\begin{array}{c}\text { L1/L2 } \\
\text { Língua e } \\
\text { Conteúdos }\end{array}$ & $\begin{array}{c}\text { Variável ao longo } \\
\text { dos anos } \\
\text { L1:10-50\% } \\
\text { L2:90-50\% }\end{array}$ & $\begin{array}{c}\text { Grupos majoritário } \\
\text { e minoritário } \\
\text { integrados }\end{array}$ & $\begin{array}{c}\text { Aditiva } \\
\text { De } \\
\text { enriquecimento }\end{array}$ \\
\hline
\end{tabular}

Portanto, para compreender como um programa funciona é necessário que se saiba como ele se relaciona com os múltiplos níveis do contexto em que está situado, incluindo a sociedade maior, a comunidade local, a escola e a sala de aula. Freeman (1998) chama a atenção para a complexidade do processo de planejamento e implementação de um programa de educação bilíngue, pois é preciso que se leve em conta o que significa educar uma população linguística e culturalmente diferente, em termos ideológicos e práticos, e como a escola e a comunidade juntas podem estabelecer objetivos e meios. Trata-se, portanto, de uma tarefa complexa, mas viável e desafiadora, como todo e qualquer empreendimento educacional. ${ }^{13}$

\section{Perspectivas futuras: à guisa de conclusão}

Prever o que ainda está por vir em termos de educação, especialmente quando se trata de educação bilíngue, pode ser um exercício de futurologia, sobretudo porque neste momento histórico em que vivenciamos rápidas e intensas transformações fica cada vez mais difícil imaginar quais serão as necessidades de nossa sociedade no futuro. Contudo, é certo que aprender outras línguas bem como apreender outras culturas são requisitos essenciais aos cidadãos globais do século XXI. A intensificação da mobilidade populacional ao redor do mundo, do contato intercultural entre cidadãos das mais diversas origens e dos avanços tecnológicos resultou numa acirrada interdependência social, econômica e política global com implicações para escola.

Se, por um lado, a escola brasileira quer preparar seus alunos para as realidades deste século, ela deve levar em conta o fato de que a diversidade cultural e linguística é a norma nas esferas local e internacional. Em termos de orientações curriculares isso

\footnotetext{
${ }^{13}$ Sobre os programas de duas línguas considerados eficazes ver Freeman (1998) e CAL (Disponível em: http://www.cal.org/twi/directory).
} 
significa que a diversidade cultural e linguística devem ser vistas como recursos, como bens culturais a serem adquiridos pelo educando, ao invés de serem ignoradas ou apagadas; em termos de práticas pedagógicas esses objetivos nos colocam o desafio de trabalhar currículos que desenvolvam a sensibilidade intercultural dos alunos, a capacidade de cruzar fronteiras linguísticas e culturais e a de manipular informações oriundas das diferentes realidades sociais, políticas e econômicas que compõem a "aldeia global"; em termos de estrutura curricular, é preciso atentar para conteúdos que desenvolvam não somente as especificidades das diversas áreas do conhecimento, mas que também proporcionem oportunidades para discussões críticas sobre questões que afetam diretamente a nossa sociedade.

Por outro lado, se a escola não assumir a tarefa de preparar cidadãos qualificados para atuarem nessa nova realidade, denominada sociedade do conhecimento ou sociedade tecnológica, onde "o conhecimento, o saber e a ciência adquirem um papel muito mais destacado que anteriormente" (LIBÂNEO; OLIVEIRA, 1998, p. 598-599), o resultado pode ser catastrófico. As modernas teorias do crescimento econômico reafirmam a importância da educação para promover o desenvolvimento do país, tendo em vista que o mercado exige pessoas multicompetentes, flexíveis, com visão do todo, que tenham conhecimento técnico e domínio das tecnologias de informática, que falem, leiam e escrevam em vários idiomas. Portanto, não é preciso ser um gênio para perceber que alimentar os recursos lingüísticos e culturais dos alunos é também uma forma de habilitá-los para o enfrentamento de novas realidades; é uma maneira de conferir poder aos cidadãos brasileiros, sobretudo àqueles que se encontram à margem da sociedade; é uma forma de equacionar a ecologia social em meio às transformações deste século. Em outros termos, educação é investimento, é desenvolvimento, é libertação, é justiça social.

\section{Referências}

AKKARI, Abdeljalil. Historical context of bilingual education. BRJ, v. 22, n. 2/3/4, University of Fribourg, Switzerland, 1998. Disponível em: <http://brj.asu.edu/v22234/articles/art2.html> Acesso em: 22 set. 2001.

BAGNO, Marcos. Novela sociolinguística. São Paulo: Contexto, 1999.

BAKER, Collin. Introduction to bilingualism and bilingual education. Clevedon, 
England: Multilingual Matters, 1993.

BORTONI-RICARDO, Stella Maris. Problemas de comunicação interdialetal. Tempo Brasileiro, v. 78/79, p. 9-32, 1984.

BRAGGIO, Sílvia Lúcia B. Línguas indígenas brasileiras ameaçadas de extinção. Relatório de Pesquisa, 1898/09 Capes, 2001.

CAVALCANTI, Marilda. Estudos sobre educação bilíngue e escolarização em contextos de minorias linguísticas no Brasil. D.E.L.T.A., v. 15, n. Especial, p. 385-417, 1999.

CUMMINS, Jim. Negotiating identities: education for empowerment in a diverse society. Ontário, CA: California Association for Bilingual Education, 1996.

The role of primary language development in promoting educational success for language minority students. In: CALIFORNIA STATE DEPARTMENT OF EDUCATION (Ed.). Schooling and language minority students: a theoretical framework. Los Angeles: California State University, Evaluation, Dissemination and Assessment Center, 1981.

FREEMAN, Rebeca. Bilingual education and social change. Clevedon, England: Multilingual Matters, 1998.

GENESEE, Fred. Learning through two languages. New York: Newbury House Publishers, 1987.

GROSJEAN, François. Life with two languages: an introduction to bilingualism. Cambridge, Mass.: Harvard University Press, 1982.

HORNBERGER, Nancy H. Teacher Quechua use in bilingual and non-bilingual classrooms of Puno, Peru. In: JACOBSON, Rodolfo; FALTIS, Christian. Language distribution issues in bilingual schooling. Clevedon, England: Multilingual Matters, 1990. p. 163-172.

Extending enrichment bilingual education: revisiting typologies and redirecting policy. In: GARCIA, Ophelia. (Ed.). Bilingual education focus in honor of Joshua A. Fishman. v. 1. Philadelphia: John Benjamins, 1991, p. 215-234.

KRASHEN, Stephen D. Second language acquisition and second language learning. Oxford: Pergamon Press, 1981.

The input hypothesis: issues and implications. Harlow: Longman, 1985.

LAMBERT, Wallace. E. The effects of bilingual and bicultural experiences on children's attitudes and social perspectives. In: HOMEL, Peter; PALIJ, Michael; AARONSON, Doris. (Eds.). Childhood bilingualism: aspects of linguistic, cognitive, and social development. Hillsdale, NJ: Lawrence Erlbaum, 1987, p. 197-221. 
OLIVEIRA, João F.; LIBÂNEO, José Carlos. A educação escolar: sociedade contemporânea. Fragmentos de Cultura, v. 8, n.3, p.597-612, Goiânia: IFITEG, 1998.

MACKEY, William. A typology of bilingual education. In: ALLEN, Harold B.; CAMPBEL, Russel N. (Eds.). Teaching English as a second language. New York: McGraw-Hill, 1972, p. 414-433.

MORAES, Marcia. Bilingual education: a dialogue with the Bakhtin Circle. New York: State University Press, 1996.

SECRETARIA DE EDUCAÇÃO FUNDAMENTAL. Referencial Curricular Nacional para as Escolas Indígenas/Ministério da Educação $e$ do Desporto, Brasília:MEC/SEF,1998.

RIBEIRO, Darcy. O povo brasileiro. São Paulo : Schwarcz, 2006[1992].

RUIZ, Richard. Orientations in language planning. In: McKAY, Sandra L.; WONG, Sau-Ling C. (Eds.). Language diversity - problem or resource?: a social and educational perspective on language minorities in the United States. Boston, Mass.: Heinle \& Heinle Publishers, 1991, p. 3-25.

SCHMIDT, Richard. Input, interaction, attention and awareness: the base for consciousness raising in second language teaching. Anais do I Encontro Nacional de Professores Universitários de Língua Inglesa, Rio de Janeiro, v. 10, 1990.

WILLIAMS, James D.; SNIPPER, Grace C. Literacy and bilingualism. New York: Longman, 1995. 